\title{
The Role of Integrated Reporting in Enhancing Corporate Transparency and Communication
}

http://doi.org/10.21272/bel.5(4).76-89.2021

Marcel Mock, ORCID: https://orcid.org/0000-0003-3018-2952

M.Sc., PhD Candidate, UCAM, Spain

Prof. Dr. Nicolás Gonzálvez-Gallego, ORCID: https://orcid.org/0000-0002-0230-1195

Full Professor, Doctor of Sciences, Faculty of Legal and Business Sciences, UCAM, Spain

Prof. Dr. Stefan Razik, ORCID: https://orcid.org/0000-0003-3705-5710

Professor, Doctor of Sciences, Scientific Director, Business Administration, FOM, Germany

\begin{abstract}
The primary purpose of the research is to analyze and evaluate the prospects for the success of Integrated Reporting in terms of its potential to increase corporate transparency and enhance corporate communication. The relevance of the decision of this scientific problem is that the European Union published a proposal for the Corporate Sustainability Reporting Directive in April 2021 that highlights the importance of intangible assets and value creation. The Directive serves to ensure companies provide consistent and comparable sustainability information. In this context, it places sustainable reporting on par with financial reporting. Systematization of the literary sources and approaches indicates that company reports developed from a financial perspective over the triple bottom line sustainability approach to an integrated approach. Moreover, stakeholders are increasingly demanding more information. Reducing information asymmetries has always been an essential task of company reports. Consequently, the primary purpose of this research is to identify whether Integrated Reporting, according to The International Integrated Reporting Framework, is a successful tool to enhance corporate transparency and communication. Integrated Reporting presents financial and nonfinancial information against the background of their contribution to value creation. Methodological tools of the research are a research synthesis and meta-analysis literature review. These instruments are developed and enriched using document analysis and systematic content analysis. The research findings suggest that integrated reports enhance transparency and communication, leading to more trust and resilience. Moreover, the results indicate that the principle-oriented framework and the Guiding Principle Materiality enable companies to respond to their specific characteristics to meet the stakeholders' requirements. The research empirically confirms and theoretically proves that Integrated Reporting can be seen as a suitable instrument for creating greater transparency, thus, a further development step in corporate reporting and communication. Integrated Reporting should therefore not be understood exclusively as a separate reporting tool but rather as a holistic management approach to implement integrated corporate management. The research results are beneficial for academic researchers and practitioners since the research provides an insightful and comprehensive overview of Integrated Reporting. Furthermore, it is also possible to derive practical recommendations for the application of Integrated Reporting.
\end{abstract}

Keywords: $\langle\mathrm{IR}\rangle$, Corporate Disclosure, Corporate Reporting, Integrated Reporting, Literature Review, Management Approach, Materiality, Transparency, Voluntary Reporting.

JEL Classification: L20, M10, M14, M40, O16.

Cite as: Mock, M., Gonzálvez-Gallego, N., Razik, S. (2021). The Role of Integrated Reporting in Enhancing Corporate Transparency and Communication. Business Ethics and Leadership, 5(4), 76-89. http://doi.org/10.21272/bel.5(4).76-89.2021.

Received: 03 November 2021

Accepted: 11 December 2021

Published: 30 December 2021

Copyright: (C) 2021 by the author. Licensee Sumy State University, Ukraine. This article is an open access article distributed under the terms and conditions of the Creative Commons Attribution (CC BY) license (https://creativecommons.org/licenses/by/4.0/). 


\section{Introduction}

In the context of the growing diversity and complexity of corporate reports, due to stakeholders' extended information needs, constantly rising regulatory requirements, and crises occurring in shorter cycles, the disclosure of decision-relevant information about companies is becoming increasingly important. In April 2021, the European Union published a proposal for a Corporate Sustainability Reporting Directive that highlights the importance of intangible assets and value creation and, in this context, places sustainable reporting on par with financial reporting (European Commission, 2021). With the new Directive, the European Union revises and strengthens the already existing rules, which the Non-Financial Reporting Directive has introduced in 2014 (European Union, 2014).

Information has always been crucial for company reports. The information triangle highlights the three dimensions of information: Information Relevance, Information Complexity, and Information focus (modified and based on Krzus, 2011: 274-275). The developing volatility-uncertainty-complexity-ambiguity environment is leading to an increasing concern on corporate information. Shareholders and stakeholders are claiming for more information to improve decision-making. However, non-financial information to support this process is scarce (Cheng et al., 2014: 91; Eccles \& Krzus, 2010: 9-10;207-208; Mishra et al., 2021; Vitolla et al., 2020: 284). At the same time, there is a risk of greenwashing (Huang \& Watson, 2015) and information overload due to an isolated-reporting trend (Bernardi, 2020: 2; de Villiers et al., 2014: 1045; Velte, 2021: 3). Despite different characteristics over the years, the reduction of information asymmetries and trust creation have always been an essential task of company reports.

The International Integrated Reporting Council (IIRC) aims to implement Integrated Reporting $(<I R>)$ as the corporate reporting norm. $\langle\mathrm{IR}>$, according to the framework of the IIRC, published in 2013 and revised in 2021, presents information directly related to their contribution to value creation. Against this background, <IR> is a holistic and multi-capital approach, which focuses on the value creation process over the short, medium, and long term. The main objective of $\langle\mathrm{IR}\rangle$ is to improve the quality of information and disclosure. In this context, $<\mathrm{IR}>$ can be defined as a reporting norm, which increases transparency and ultimately supports investors' decision-making process (International Integrated Reporting Council (IIRC), 2021). <IR> complies with the applicable directives of the European Union and is becoming increasingly important due to the multicapital approach of the Corporate Sustainability Reporting Directive.

This paper aims to provide valuable insights and a comprehensive overview of $\langle\mathrm{IR}\rangle$ and determine the contribution of $\langle\mathrm{IR}>$ to create greater transparency. The primary purpose is to identify to which extent $<\mathrm{IR}>$ can be assumed to be a successful tool for decreasing information asymmetry and creating corporate transparency to increase the stakeholders' trust. Finally, the benefits and the weaknesses of $<\mathrm{IR}>$ will be outlined to give the reader a comprehensive overview of this reporting norm. This study enriches previous research on $\langle\mathrm{IR}>$ by showing its importance for management theory. In sum, this research contributes to spreading the idea $\langle\mathrm{IR}\rangle$ within the corporate reporting landscape. Besides, the study continues the reflection on the further development of corporate reporting. The paper proceeds as follows. The following section provides concise background information highlighting the critical aspects of information asymmetry, 〈IR>, and especially the Guiding Principle Materiality. After the theoretical framework, the methodology of this paper is explained in detail. Subsequently, the main results are presented and discussed in a focused manner. Afterwards, the limitations of this paper are pointed out, and possible fields of research are suggested. Finally, the concluding section gives an outlook.

\section{Theoretical Background and Context}

Information and the Role of Corporate Reporting. Information and corporate reporting are two inseparable elements of financial communication. However, the current status quo of financial reporting was conceived in the 1930s. Therefore, it can be assumed that the reporting situation does not meet the requirements of the relevant stakeholders and thus does not provide any benefit for those as mentioned above. The focus of reporting is too retrospective and less oriented towards how the company intends to achieve performance in the future. In this respect, it can be concluded that financial reporting in its current form generates less decisionrelevant information than benefits for shareholders and stakeholders. Although other reporting formats already exist, they still lack an adequate interdependence between financial and non-financial information, which is considered more important than ever (Krzus, 2011: 274; Vitolla et al., 2020: 282; 284). These considerations can be manifested through various conceptual theories and underline the rationale for more voluntary and integrated reporting (Camilleri, 2018: 569). In this context, it is first necessary to look at agency theory. Within this theory's framework, executives (as agents of their principals) maximize shareholder value. According to 
Eisenhardt (1989), both the agents' and the principals' motivation was that both parties could maximize their utility. Due to the constellation of the so-called agency relationship (Jensen \& Meckling, 1976: 308), it can be assumed that information asymmetries and the resulting potential for conflict will arise (Pfaff \& Zweifel, 1998: 184; Spremann, 1990: 562-563). A possible solution to these agency problems and asymmetries can be regular reporting, creating the necessary transparency (Spence, 1973: 355). Furthermore, the stewardship theory can be used to explain reporting efforts. This theory can be understood as a counterpart to the agency theory (Dumay et al., 2019: 29), as it assumes that managers pursue collective and trustworthy purposes (Davis et al., 1997: 20). The theory indicates that collaborative behaviour generates utility.

However, as can be seen from the evolution of corporate reporting, reports often lack a holistic or integrated approach that considers social and environmental dimensions in addition to economic aspects (Adams et al., 2016). Legitimacy theory indicates a social contract between the organization and its society (Shocker \& Sethi, 1973: 97). That means that the organization's reporting reflects and meets the environment's expectations (Camilleri, 2015; Deegan \& Unerman, 2011: 325). Since stakeholders and the environment no longer demand economic reporting alone, reporting environmental and social levels is also necessary. To be considered legitimate, organizations are therefore required to orient themselves to these norms and expectations (Deegan \& Unerman, 2011: 323). Institutional theory is closely interwoven with legitimacy theory, as it assumes that based on institutional pressure, the organization is rewarded with higher legitimacy (Meyer \& Rowan, 1977). The approach to voluntary reporting can thus be explained by a kind of market pressure exerted by stakeholders and competition or governments and institutions (Camilleri, 2018: 570-571). Against this background, the article first discusses the concrete information approach according to Krzus (2011), which is also supported by Vitolla et al., 2020 as well as Mishra et al., 2021, and then abstract his considerations to generally valid conceptual theories to derive the necessity of a holistic and integrated reporting system. Krzus' (2011) approach supplemented by another component (namely information focus) thus results in three essential dimensions of information.



Figure 1. Information Triangle

Source: Developed by the authors based on Krzus, 2011: 274-275

Firstly, there is the need to look at information relevance. Stakeholders increasingly demand more information (Cortesi \& Vena, 2019: 745; Dumay et al., 2016: 177). Precise knowledge of a company's strategic value drivers is required to make external investment decisions and internal management decisions, although this can only be extracted in very rudimentary form from current corporate reports (Krzus, 2011: 274; La Torre et al., 2018: 342-343). Another indicator of the increasing information relevance and incongruence with traditional financial reporting is that, according to studies, intangible assets increasingly contribute to market value (Elsten \& Hill, 2017: 245). It gets clear that financial reporting should provide considerably more information on its intangible assets since they become more relevant and though have higher importance for the decision-making process of shareholders and stakeholders (Bernardi, 2020: 1; Massingham et al., 2019: 63-65).

Secondly, information and its presentation are becoming increasingly complex and create uncertainty instead of transparency (Financial Reporting Council, n.d: 28; Hartanto et al., 2020: 47). Among other things, this is because further reports have been added or the requirements, both regulatory and market-driven, have been continuously raised as part of the increasing need for information. In some cases, requirements have been 
retained that may no longer be appropriate due to corporate practice changes. These circumstances ultimately lead to increased duplications and redundancies, which are not conducive to the relevant (de Villiers et al., 2014: 1043; Hannen, 2017: V). In this context, internal, preparation-related resources and external, appreciation-related resources are wasted (Krzus, 2011: 275). As a result, corporate reporting no longer meets its primary objectives of reducing information asymmetry and thus increasing transparency. Finally, information focus is more critical than ever to avoid redundancies and increase corporate reporting transparency. It means that the focus of information must be readjusted or even realigned. Information disclosed as part of corporate reporting must be measured against its future orientation and its extent to deliver substantial value for shareholders and stakeholders within their decision-making processes (Sriani \& Agustia, 2020: 2). Against this background, company reports, which were initially based almost exclusively on financial indicators, developed from the triple bottom line sustainability approach to an integrated approach. A method that combines the three dimensions of information meets the requirements of the agency, stewardship, institutional as well as legitimacy theory, and emphasizes the value creation of a company will be presented in the following chapter.

Integrated Reporting According to the International <IR> Framework of the IIRC. In the context of investment decisions, decision-makers increasingly suffer a lack of information, which can be explained on the one hand by the rise in information relevance and on the other hand by the growth in information complexity (Cheng et al., 2014: 91; Eccles \& Krzus, 2010: 9-10; 207-208). Besides this, there are also emerging tendencies that the addressees of corporate reports are exposed to the risk of a so-called greenwashing (Huang \& Watson, 2015) and information overload (Bernardi, 2020: 2; de Villiers et al., 2014: 1045; Velte, 2021:3). 〈IR>, however, aims to implement a holistic and efficient corporate reporting approach that is aligned to the readers' expectations. It should create more transparency and, thus, better information quality (Sriani \& Agustia, 2020). For that reason, the framework, published in 2013, is currently in a consultation phase to evaluate its content and meet changing market needs. The IIRC's long-term vision and the aim are to establish <IR> as the corporate reporting norm (International Integrated Reporting Council (IIRC), 2021: 2; 5). An integrated report is defined by the (International Integrated Reporting Council (IIRC), 2021: 10) as follows:

An integrated report is a concise communication about how an organization's strategy, governance, performance and prospects, in the context of its external environment, lead to the creation, preservation or erosion of value over the short, medium and long term.

The <IR> Framework covers three Fundamental Concepts, seven Guiding Principles and eight Content Elements to grant a value-added-based communication. The three components are summarised in Table 1.

Table 1. Overview of The International <IR> Framework

\begin{tabular}{|c|c|c|}
\hline Fundamental Concepts & Guiding Principles & Content Elements \\
\hline \multirow{8}{*}{$\begin{array}{l}\text { - Value creation for the organisation } \\
\text { and others } \\
\text { - The Capitals } \\
\text { - The value creation process }\end{array}$} & - Strategic focus and future orientation & $\begin{array}{l}\text { - Organisational overview and external } \\
\text { environment }\end{array}$ \\
\hline & - Connectivity of information & - Governance \\
\hline & - Stakeholder relationships & - Business model \\
\hline & - Materiality & - Risk and opportunities \\
\hline & - Conciseness & - Strategy and resource allocation \\
\hline & - Reliability and completeness & - Performance \\
\hline & - Consistency and comparability & - Outlook \\
\hline & & - Basis of preparation and presentation \\
\hline Source: IIRC, 2021, pp. 15-23. & Source: IIRC, 2021, pp. 25-37. & Source: IIRC, 2021, pp. 38-48. \\
\hline
\end{tabular}

Source: Systematized by the authors based on International Integrated Reporting Council (IIRC), 2021, pp. 15-23

It should be prefaced by noting that a principles-based approach is inherent in the framework. A few small requirements must be met to be considered an integrated and framework-compliant report. However, one should note that no details to be published are mandatory. It is to achieve an efficient balance between flexibility and prescription (Busco et al., 2013: 12-13; International Integrated Reporting Council (IIRC), 2021: 5 and Sect 1D: 11; Vena et al., 2020: 194). In concrete terms, this means that companies can decide on their responsibility which information they consider material and which information they want to publish in their reports (International Integrated Reporting Council (IIRC), 2021: 5 and Sect. 1C and 1D: 11). As already stated, an integrated report's primary purpose is to disclose the added value of an organization and how it creates this for exclusively itself and others. External influences determine this value creation (International Integrated Reporting Council (IIRC), 2021: Sect. 2B, 16-17). The Capitals represent the success factors of a 
company and are summarized under the second fundamental concept. They are regarded as essential parameters of value creation. The Framework differentiates between Financial, Manufactured, Intellectual, Human, Social and Relationship, and Natural Capital (International Integrated Reporting Council (IIRC), 2021: Para. 2.15, 18-19). The value creation process is the third fundamental concept. In schematic terms, the Capitals are defined as an input transformed into an output within the value creation process. The organization's business model, which in turn is determined by the external environment, the purpose, mission and vision, and the governance, forms the decisive basis and design of the transformation process. The values are created, preserved, or eroded (International Integrated Reporting Council (IIRC), 2021: Sect. 2D, 21-23). The high degree of abstraction requires an indispensable way to operationalize this theoretical construct. For this reason, seven Guiding Principles and eight Content Elements were defined by the IIRC. The Guiding Principles serve as guidelines for preparing an integrated report and preparing and presenting information to be published (International Integrated Reporting Council (IIRC), 2021: Para. 3.1, 25). Within the Guiding Principles' scope, the maxim of the principles-based approach of the Framework becomes very clear. Thus, this approach makes the published information and reports very individual to the company and less comparable in the peer group (International Integrated Reporting Council (IIRC), 2021: Sect. 1D, 11). One central aspect of the principlesbased approach is the Guiding Principle Materiality (Gerwanski et al., 2019; International Integrated Reporting Council (IIRC), 2021: Sect. 3D, 29-31; Mio et al., 2020), which will be described in detail in the next section. The Content Elements were formulated (International Integrated Reporting Council (IIRC), 2021: Para 3.56, 37 and Para. 4.3, 38; Velte \& Stawinoga, 2017:296) to ensure a certain level of comparability and to concretize the Guiding Principles. The eight Content Elements serve to operationalize the requirements of the Framework. The Content Elements are not presented in the form of concrete requirements to remain faithful to the principlebased approach in this Framework but allow a company-specific scope by formulating them as questions (International Integrated Reporting Council (IIRC), 2021: Para. 4.3, 38).

According to previous research, the implementation and application of $\langle\mathrm{IR}\rangle$ have several advantages (e.g., Massingham et al., 2019: 63; Vitolla \& Raimo, 2018). The potential benefits of <IR > are both internal and external. Essentially, communication and risk management benefits and cost benefits are to be mentioned in this context (Eccles \& Krzus, 2010: 146-161 as quoted in Roth, 2014: 65). DUE TO ITS COMPREHENSIVE FOCUS, <IR> can also be understood as a holistic management tool. The intention to present information in an aggregated and material way favors the consolidation and harmonization of the strategy with the requirements of the organization's different stakeholders (Haller, 2017: 443). The development of the reporting landscape towards $<\mathrm{IR}>$ is indispensable, as the symbiosis of financial and non-financial and value-oriented and sustainable information is increasingly expected and requested (Haller, 2017: 442). The overview of the Framework and the selection of benefits associated with the application of <IR> already allow initial conclusions to be drawn that $\langle\mathrm{IR}>$ makes a significant contribution to increasing transparency in the context of corporate reporting.

$<I R>$ and the Guiding Principle Materiality in the Context of Creating Transparency. One of the primary Guiding Principles is Materiality. That means that integrated reports should emphasize and disclose information that substantively affects the organization and its ability to create value (Lai et al., 2017: 534-535). Thus, the focus on materiality leads automatically to increased transparency and a more efficient decisionmaking process for share- and stakeholders. It is important to note that the materiality determination process involves both negative and positive subjects as wells as risks and opportunities that occur within the value creation process of an organization and covers financial and non-financial information (International Integrated Reporting Council (IIRC), 2021: Para. 3.18 and 3.19, 29-30).

The materiality determination process comprises four sub-process steps. The first step is to identify relevant facts and circumstances that contribute to the value creation process. Relevant information in some way impacts a company's value creation process or its ability to create value. In this context, it is essential to adopt the stakeholders' different perspectives to incorporate the diversity of relevant information. Besides, it must be considered that not exclusively, quickly determined, short-term information is included, but furthermore also that anticipates medium to long-term effects, even if these are sometimes difficult to interject (International Integrated Reporting Council (IIRC), 2021: Para. 3.21-3.23, 30). Subsequently, the identified characteristics must be evaluated and reflected upon concerning their already demonstrable or potentially expected impact on value creation. Thus, the magnitude and the likelihood of its occurrence need to be determined. In this context, information can be considered material either individually or entirely. However, the effects need not exclusively be quantified. It might be sufficient to evaluate qualitatively if it is more appropriate. In sum, the process of assessing the importance covers quantitative and qualitative factors as well as financial, operational, strategic, reputational, and regulatory perspectives. 
Moreover, it must be considered whether these effects have an internal or external effect, and the time frame needs to be considered (International Integrated Reporting Council (IIRC), 2021: Para. 3.24-3.27, 30-31). Based on the evaluation, a prioritization must be made according to the individual issues' relative importance (International Integrated Reporting Council (IIRC), 2021: Para. 3.28, 31). Finally, it needs to be decided which information the company will ultimately disclose in its Integrated Report. In this respect, the organization's management needs to consider different perspectives and internal and external effects (International Integrated Reporting Council (IIRC), 2021: Para. 3.29, 31; Lai et al., 2017: 537-538). However, the key to the materiality determination process is the reporting boundary concept (Biondi et al., 2020: 896; International Integrated Reporting Council (IIRC), 2021: Para. 3.29, 31).

Against the background of the definitional features mentioned above, the Guiding Principle Materiality can be interpreted in a wide variety of ways. For example, a company's characteristics, such as its industry sector, size, or target/stakeholder group, play an essential role. The essential feature of the principles-based approach of $\langle\mathrm{IR}\rangle$ is also reflected in the materiality determination process. There are no fixed rules that prescribe the frequency and the exact procedure for determining materiality. Instead, companies are required to make discretionary decisions to do justice to each company's characteristics. Against this background, it is essential that the materiality determination process finds its way into the management processes and decisions of a company so that Integrated Thinking ${ }^{1}$ is ultimately also strengthened. In short, the consistent application of the Guiding Principle Materiality is intended to improve internal and external decision-making by limiting unnecessary information and aspects but focusing on core topics instead. This, in turn, leads to an increase in the quality of the information published (International Integrated Reporting Council (IIRC), 2015: 4).

\section{Methodology}

The methodology of this study follows a qualitative approach. This methodology is so useful because, according to Velte \& Stawinoga (2017), the research field of integrated reporting remains relatively unexplored, and an exploratory approach, therefore seems most appropriate. The qualitative design of this study follows the idea of a literature review and a corresponding document analysis. Since literature reviews have several goals and purposes, ${ }^{2}$ it is necessary to define the literature review used in this study in detail. Massaro et al. (2016) describe a literature review continuum that shows the different types of reviews. According to their analysis, some reviews may have almost no rules (rapid review) and some with a rigid set of rules (structured literature review) (Massaro et al., 2016: 769). Although (Denyer \& Tranfield, 2006: 216) state that the traditional literature review is the most common technique in management research, the study's claim goes beyond this type of review. Traditional authorship reviews are not comprehensive or even balanced (Petticrew \& Roberts, 2008: 5). Therefore, a more structured method is preferred to minimize subjectivity and bias while maintaining the researchers' expertise in this field (Petticrew \& Roberts, 2008: 10). Considering the previously mentioned aspects, this study is therefore based on research synthesis and meta-analysis literature review. According to (Massaro et al., 2016: 771-772), individual elements of a structured literature review were nevertheless applied to give the review an adequate structure. ${ }^{3}$ The methodology of this paper is largely based on Tranfield et al. (2003), who formulated a review approach for management studies, to answer the research questions described below. This approach aims to summarise research findings in a systematic, reproducible, and transparent way to expand current scientific knowledge and provide a practical contribution.

First, a literature review protocol needs to be defined, which sets up the research project. As already stated, this paper aims to identify whether $<\mathrm{IR}>$ is a successful tool to enhance corporate transparency. This objective leads directly to whether $<\mathrm{IR}>$ appears to be suitable as such a tool, what criticisms are associated with it and what future implications the results obtained have for research. Therefore, the following research questions were formulated:

RQ1: Can <IR> be seen as a suitable tool for increasing transparency in corporate reporting?

RQ2: Is the focus on Materiality suitable for increasing transparency?

Afterwards, the author selected articles primarily from literature databases, journals found through the literature search engine Web of Science and Google Scholar (GS) because these are the most appropriate data

\footnotetext{
${ }^{1}$ Integrated Thinking is defined as: 'The active consideration by an organization of the relationships between its various operating and functional units and the capitals that the organization uses or affects. Integrated thinking leads to integrated decision-making and actions that consider the creation, preservation or erosion of value over the short, medium and long term.' (International Integrated Reporting Council (IIRC), 2021: 53).

${ }^{2}$ Literature Reviews may be used, such as a guide for future studies, summaries, and elder theories. Cf. Petticrew \& Roberts, 2008.

${ }^{3}$ The ten steps are the following: 1. Protocol, 2. Question, 3. Literature search, 4. Article impact, 5. Analytical framework, 6. Reliability, 7. Validity, 8.

Code, 9. Insights and 10. Future research paths and questions. Cf. Massaro et al., 2016: 771-772.
} 
warehouses for literature reviews (Martín-Martín et al., 2018). The literature review was conducted in July and August 2021. The articles were selected in case the terms "integrated reporting" or "Integrated Reporting" and "materiality" and "transparency" appear in the article's title, abstract, or keywords. ${ }^{4}$ The databases and searches strings were limited to English articles and nor journals were excluded to find as many relevant articles as possible. Moreover, they need to have been published between 2013 and 2021 to grant topicality and relevance. Both theoretical and practical research were considered. The search algorithm is as follows:

"Integrated Reporting" + (Materiality OR Transparency); -isbn; custom range: 2013-2021; exclude patents; exclude quotations; language: English

As a result, the authors identified 8,880 articles. Due to the great amount of research, the authors decided to adapt and to restrict their algorithm to the abstract of the papers:

Abstract: "Integrated Reporting" + (Materiality OR Transparency); -isbn; custom range: 2013-2021; exclude patents; exclude quotations; language: English

As a result, the authors identified 7,230 articles. Due to the still great amount of research, the authors decided to adapt and restrict their algorithm to the title of the papers. The authors agreed that the title is the most informative medium of a research paper, and thus, it can be assumed that the accentuated topics must appear in the title. It ensures that the focus is on truly essential papers. However, the large number of available research papers indicates to the authors of this study that this is a substantial field of research in need of an overviewcreating literature review. It also underlines the relevance of the topic. The final algorithm is as follows:

Allintitle: "Integrated Reporting" + (Materiality OR Transparency); -isbn; custom range: 2013-2021; exclude patents; exclude quotations; language: English

This search brings out an already limited result. Based on the algorithm, 26 articles could now be identified. On this basis, the researchers used the titles and abstracts to check whether the studies corresponded to the research questions. Only three book chapters were excluded against the background of the already very narrow search algorithm. It left 23 potential articles that require a more stringent and in-depth analysis. The full texts were independently reviewed; any discrepancies were resolved in a discussion. Further exclusion criteria were defined as part of the analysis. If at least one of the following criteria was met, the article was excluded:

1. The article did not address <IR > according to the IIRC Framework.

2. The article did not focus on the Guiding Principle Materiality.

3. The article did not address transparency in relation to $\langle\mathrm{IR}>$ or the Guiding Principle Materiality.

4. The article does not show cites or cites per year $>1$.

Since Google Scholar was used as a database, exclusion criterion no. 4 also seemed relevant to the authors, as this meant that scientifically less significant contributions could be sorted out. 14 articles met at least one of the exclusion criteria mentioned above, so that they were subsequently excluded. Finally, 9 articles are taken into consideration for this research. The researchers attribute the relatively low number of identified papers on the one hand to the strictly defined research framework and on the other hand to the existing potential of their research question to gain further knowledge in this sub-area of the $\langle\mathrm{IR}\rangle$. Afterwards, the impact of the identified articles was measured according to both the number of Google Scholar citations and the citation per year (Biemans et al., 2010: 462; Dumay et al., 2016: 170; Garfield, 1989: 5). Table 3, in the following section, provides an overview of all the identified articles. The relevant articles were evaluated using document analysis and systematic content analysis to filter out both the insights and future research paths and questions. According to Mayring (2016: 134), the qualitative design of this study is based on document analysis. The global analysis proposed to Legewie (1994) was used to analyze the relevant documents. The global analysis includes ten steps that allow an adequate analysis of the papers. The dedicated process steps, which build on each other, enable both an efficient and standardized and in-depth analysis of the underlying documents. The entire process is shown in Table 2 (Legewie, 1994: 178-181).

Table 2. Global Analysis According to Legewie (1994)

\begin{tabular}{|c|l|}
\hline \multicolumn{2}{|c|}{ Global analysis according to Legewie (1994) } \\
\hline Step & Description \\
\hline I & Orientation: First overview of the document \\
\hline II & Activating context knowledge: Prehistory and context of the document \\
\hline
\end{tabular}

\footnotetext{
${ }^{4}$ By analogy with Dumay et al., 2016, the authors of this study also use the term "article" to refer to "conference papers" as well as to "journal articles" (Dumay et al., 2016: 170).
} 
Table 2 (cont.). Global Analysis According to Legewie (1994)

\begin{tabular}{|c|l|}
\hline III & Work through text: Careful reading and interpretation of the text \\
\hline IV & Devise ideas: Listing of major ideas \\
\hline V & Create a keyword index: Presentation of priority problems and topics \\
\hline VI & Summary: Analytical order of the most important topics in 30-50 lines \\
\hline VII & Evaluation of the text: Short statement on the communication situation \\
\hline VIII & Evaluation keywords: Classification of the text according to its relevance to the research question \\
\hline IX & Consequences for further work: Planning the further processing of the text \\
\hline X & Presentation of results: Summary of work results \\
\hline
\end{tabular}

Source: Legewie, 1994: 178-181

After defining the qualitative research design, it is necessary to find concrete research procedures. Since this paper is secondary research induced, the researchers of this study collect their data by using existing information and data and do not produce any kind of it (Flick, 2018: 61). To align with the general research design, the method of selective, content-structuring analysis, according to Mayring $(2014 ; 2016)$, is used to examine the relevant articles. The aim is to filter and summarise certain aspects. The content is derived from the theoretical backgrounds which have been mentioned before. The chosen evaluation technique is qualitative content analysis (Mayring, 2014; 2016). Qualitative content analysis is characterised by the fact that the material is systematically worked through and analyzed (Mayring, 2016: 114). This systematic and pre-defined process should make it possible to gain new insights to explore and expand the understanding and knowledge of the research subjects (Krippendorff, 2019: 24).

\section{Findings}

First, it is necessary to assess the "citation classics" (Garfield, 1989: 5), namely the total citations and the citation per year index, to get an idea about the article impact (Baldi, 1998: 892; Biemans et al., 2010: 462) of the identified articles. The citations per year are also considered to counteract the accumulation of many citations of older articles (Dumay \& Dai, 2014: 270). The citation data were downloaded from Google Scholar as of 11 August 2021. The articles are sorted due to their Google Scholar ranking. However, the ranking was adapted since the authors applied certain exclusion criteria, which have been explained earlier. When analyzing the citations per year, it is obvious, in this research study, that more recent articles have a high metric. For the authors, this indicates a strong academic interest in $\langle\mathrm{IR}\rangle$ and its impact on corporate reporting. The Google Scholar metrics are shown in Table 3.

Table 3. Google Scholar Metrics on Identified Articles

\begin{tabular}{|l|l|l|c|c|}
\hline \multicolumn{1}{|c|}{ Reference } & \multicolumn{1}{|c|}{ Article } & Citations & $\begin{array}{c}\text { Citations per } \\
\text { year }\end{array}$ \\
\hline $\mathbf{1}$ & Lai et al., 2017 & $\begin{array}{l}\text { What does materiality mean to integrated reporting } \\
\text { preparers? An empirical exploration }\end{array}$ & 87 & 21.75 \\
\hline $\mathbf{2}$ & Fasan \& Mio, 2017 & $\begin{array}{l}\text { Fostering stakeholder engagement: The role of } \\
\text { materiality disclosure in integrated reporting }\end{array}$ & 127 & 31.75 \\
\hline $\mathbf{3}$ & Gerwanski et al., 2019 & $\begin{array}{l}\text { Determinants of materiality disclosure quality in } \\
\text { integrated reporting: Empirical evidence from an } \\
\text { international setting }\end{array}$ & 49 & 24.5 \\
\hline $\mathbf{4}$ & Green \& Cheng, 2019 & $\begin{array}{l}\text { Materiality judgments in an integrated reporting } \\
\text { setting: The effect of strategic relevance and } \\
\text { strategy map }\end{array}$ & 31 & 15.5 \\
\hline $\mathbf{5}$ & Cerbone \& Maroun, 2020 & $\begin{array}{l}\text { Materiality in an integrated reporting setting: } \\
\text { Insights using an institutional logics framework }\end{array}$ & 21 & 21.0 \\
\hline $\mathbf{6}$ & Wee et al., 2016 & $\begin{array}{l}\text { Factors affecting preparers' and auditors' } \\
\text { judgements about materiality and conciseness in } \\
\text { integrated reporting }\end{array}$ & 18 & 3.6 \\
\hline $\mathbf{7}$ & Nistor et al., 2019 & $\begin{array}{l}\text { Approaching public sector transparency through } \\
\text { an integrated reporting benchmark }\end{array}$ & 7 & 3.5 \\
\hline $\mathbf{8}$ & Mio \& Fasan, 2014 & $\begin{array}{l}\text { The determinants of materiality disclosure in } \\
\text { integrated corporate reporting }\end{array}$ & 20 & 2.86 \\
\hline $\mathbf{9}$ & Mio et al., 2020 & $\begin{array}{l}\text { Materiality in integrated and sustainability } \\
\text { reporting: A paradigm shift? }\end{array}$ & 16 & 16.0 \\
\hline
\end{tabular}

Source: Developed and systematized by the authors.

Table 4 summarizes the main results and the key findings of the identified studies concerning transparency and the Guiding Principle Materiality within the context of $\langle\mathrm{IR}\rangle$. In addition, the methodology is also listed to provide a better overview of how new findings were obtained or hypotheses verified. 
Table 4. Overview of Methodology and Key Findings

\begin{tabular}{|c|c|c|c|}
\hline & Reference & Methodology & Key findings \\
\hline 1 & Lai et al., 2017 & $\begin{array}{l}\text { Case Study } \\
\text { In-depth semi-structured interviews }\end{array}$ & $\begin{array}{l}\text { Materiality corresponds with the corporate strategy. } \\
\text { The materiality determination process is driven by a small group in } \\
\text { cooperation with the Chief Financial Officer. }\end{array}$ \\
\hline 2 & Fasan \& Mio, 2017 & $\begin{array}{l}\text { Several statistical analyses, including an OLS regression } \\
\text { analysis } \\
\text { Hand-collected dataset }\end{array}$ & $\begin{array}{l}\text { Main characteristics for the relevance of materiality disclosure are size } \\
\text { and diversity of board whereas the legal environment is not relevant. } \\
\text { <IR }>\text { pilot companies disclose more materiality information. }\end{array}$ \\
\hline 3 & Gerwanski et al., 2019 & $\begin{array}{l}\text { Hand-collected materiality disclosure quality score } \\
\text { Cross-national sample of } 359 \text { firm-year observations }\end{array}$ & $\begin{array}{l}\text { The quality of materiality information is positively associated with } \\
\text { learning effects, gender diversity and assurance of non-financial } \\
\text { information. } \\
\text { The quality of materiality information is not associated with the } \\
\text { readability, the company's listing, and earnings management. }\end{array}$ \\
\hline 4 & Green \& Cheng, 2019 & Experiment & $\begin{array}{l}\text { To assess materiality, it is essential to consider the client's strategy in } \\
\text { the relevant process. }\end{array}$ \\
\hline 5 & Cerbone \& Maroun, 2020 & $\begin{array}{l}\text { Interviews with } 20 \text { preparers from } 14 \text { organisations listed on the } \\
\text { Johannesburg Stock Exchange }\end{array}$ & $\begin{array}{l}\text { The materiality strategy depends on the underlying institutional logic. } \\
\text { A process is taking place from lengthy to comprehensive reporting, } \\
\text { including the presentation of the value creation process and ensuring } \\
\text { sustainability. }\end{array}$ \\
\hline 6 & Wee et al., 2016 & $\begin{array}{l}\text { Interviews with preparers of corporate reports, data collection } \\
\text { about the materiality determination process from disclosures in } \\
195 \text { corporate reports issued in 2012/13, and behavioural } \\
\text { experiment with corporate report preparers and auditors }\end{array}$ & $\begin{array}{l}\text { The procedures used by the companies to determine materiality are } \\
\text { essentially based on the IIRC Framework. Although this process is } \\
\text { disclosed in the reporting, the prioritisation of the aspects is not. }\end{array}$ \\
\hline 7 & Nistor et al., 2019 & Content analysis and cluster analysis & $\begin{array}{l}\text { The analysis shows that the level of disclosure was very high. It was } \\
\text { also evident that municipalities in the Anglo-Saxon and Northern Local } \\
\text { public administration had the highest level of disclosure. }\end{array}$ \\
\hline 8 & Mio \& Fasan, 2014 & Cross sectional regression model & $\begin{array}{l}\text { Disclosure and reporting on materiality are not company-specific but } \\
\text { rather industry-specific. This supports the prevailing view in the } \\
\text { literature that industry is the key driver of voluntary disclosure. }\end{array}$ \\
\hline 9 & Mio et al., 2020 & Content analysis and interviews & $\begin{array}{l}\text { The implementation of materiality depends on whether it is for }\langle\mathrm{IR}> \\
\text { (market logic) or sustainability reporting (stakeholder logic). Topics that } \\
\text { are identified relevant for <IR }>\text { are considered more important for the } \\
\text { market whereas issues identified within the context of sustainability } \\
\text { reporting are more important for stakeholders. Results suggests three } \\
\text { main differences in materiality: intrinsic nature of materiality, } \\
\text { stakeholders' expectations on materiality and the operationalization of } \\
\text { materiality. }\end{array}$ \\
\hline
\end{tabular}

Source: Developed and systematized by the authors 
It is evident that materiality and the associated materiality determination process are to be positively assessed in the context of integrated reporting. The findings suggest that integrated reports enhance transparency, leading to more trust and resilience. To crystallize the importance of the materiality determination process and materiality in integrated reports, the IIRC has already published guidance for preparing integrated reports in 2015 (International Integrated Reporting Council (IIRC), 2015). Moreover, the results indicate that the principle-oriented framework, especially the Guiding Principle Materiality, enables companies to respond to their specific characteristics to meet the stakeholders' requirements. Reporting that is both sustainable, integrated and tailored to the expectations of all relevant stakeholders of a company increases the transparency and quality of the disclosed content and contributes to the future orientation of corporate management and monitoring. In conclusion, <IR> can be seen as a suitable instrument for creating more transparency in corporate reporting and thus as a further development step in corporate reporting.

In addition to the tabulated results, the authors of this study have noticed other important points. (Lai et al., 2017) addresses implementation of the Guiding Principle Materiality by conducting in-depth interviews with <IR> preparers. According to them, there is a connection and a corresponding significance of materiality with the defined corporate strategy. Through $\langle\mathrm{IR}\rangle$, strategic requirements would be specified and transformed into measures and results based on their prioritization. It is, therefore, less decisive which information is included or excluded in the reporting process. The context in which the materiality determination process and materiality reporting occur play an essential role in a company not to lose credibility and trust in the capital market (Lai et al., 2017: 548). Moreover, the results of Preuß et al. (2019) indicate that integrated reports increasingly focus on materiality and conciseness principles (Preuß et al., 2019: 111).

According to Kolk (2008), the analysis shows that companies increasingly use corporate governance and sustainability reporting to fulfil accountability and increase transparency to their relevant stakeholders. According to these measures, the process of determining materiality in 〈IR> seems to confirm this convergence of disclosing material issues and prioritizing them and shaping their corporate governance. This is in line with the findings of Fasan \& Mio (2017). The results of their analyses show that companies using the IIRC framework have done a significantly better job of disclosing materiality than those companies that do not. If nothing else, this reinforces the trust and usefulness of the work done through the IIRC. It is to strike a balance between comparability and credibility, which is achieved through the management of materiality. Thus, it will allow investors and other stakeholders to assess the potential of that company to create value. Fasan \& Mio (2017) conclude that a materiality determination process is a powerful tool for stakeholder engagement (Fasan \& Mio, 2017: 303).

Finally, the authors of this study also find authoritative results on materiality studies in a contribution by Gerwanski et al. (2019). In their study, the authors break down the disclosure of materiality into its individual but significant components: establishing context, identification, analysis, evaluation, treatment, and publication. Their findings in this regard show that in practice, companies should place more emphasis on the disclosure of the materiality matrix, provide more information on time horizons, and not only assess and communicate opportunities but also material business risks (Gerwanski et al., 2019: 763).

\section{Limitations and Implications for Future Research Fields}

Despite the researchers' analytically structured approach, this paper also has limitations. The limitations mentioned below should be taken up for future research and, if necessary, considered or included. In general, the limitations of qualitative research go hand in hand with this study. In particular, the limitations of a qualitative document analysis must also be considered in this context. It is evident that despite all the structure in the study, the document analysis can only cover partial and specific aspects of all information and cannot preserve objectivity in its entirety. Therefore, this research may suffer a certain degree from subjectivity. In particular, the interpretation and schematization of the underlying texts and their contexts can be identified as significant challenges of the research design (Flick, 2018: 383). Moreover, one should note that $<\mathrm{IR}>$ is only one of many frameworks that can be used to create greater transparency. Therefore, future research should analyze and compare different frameworks concerning their contribution to corporate transparency. This paper gives first indications, but these will need to be specified in the future. Besides, it would be interesting for future studies to determine how the degree of increase in transparency depends on certain factors, such as industry, company size, company performance, or board diversity. In this context, many possible research areas arise based on the study presented here. However, the paper follows Dumay's et al. (2016: 178-180) formulated call to contribute and extend the understanding of $\langle\mathrm{IR}>$ and its emerging academic attention. 


\section{Conclusions and Outlook}

This research aims to provide valuable insight and a comprehensive overview $<\mathrm{IR}>$. The paper investigates the contribution of $\langle\mathrm{IR}>$ to increase transparency within corporate reporting. This research contributes to the knowledge of corporate reporting and the spread of $\langle\mathrm{IR}\rangle$ by revealing theoretical and practical implications related to the application of $\langle\mathrm{IR}\rangle$ and adds value in this respect. It is necessary to overcome the information overload and the incongruence of information in the various reports to make the levels of information relevance, information focus, and information complexity as fully accessible as possible to the addressee of the report (Eccles \& Krzus, 2010). Due to this fact, $\langle\mathrm{IR}>$ continues to gain increasing momentum. It is essential that all material aspects, regardless of whether they have a positive or negative impact on the company, are concisely identified and communicated to achieve these goals in the best possible way. In this way, it is possible to create transparency and enable the company's investors to allocate their capital efficiently (Gerwanski et al., 2019: 763). Beyond these theoretical considerations, the study also has several practical implications. Findings are particularly relevant for managers, shareholders, and policymakers. It is always commendable to question the meaningful application of this framework, especially the Guiding Principle Materiality. However, the framework will not be suitable to reflect the non-financial activities of every company correctly.

In sum, however, <IR> based on the IIRC's framework should not be understood exclusively as a new, additional reporting format. Instead, when fully integrated and adapted, it can serve as an indispensable and, at the same time, holistic and integrated management approach that can add significant value for both shareholders and stakeholders as well as for the organization itself (International Integrated Reporting Council (IIRC), 2021: Para. 4.29, 44). Holistically integrated reporting is designed to uncover a company's central value-creation factors and provide stakeholders with decision-relevant information to make their decisions efficiently. However, this type of reporting does not merely add value for the external audience but also enables management to align corporate governance in a multidimensional way. This multidimensional interdisciplinarity is expressed in holistic and integrated thinking, in consideration of influencing interdependencies and the materiality assessment of specific information (Haller, 2017: 443). By emphasizing materiality, two aspects can be influenced in corporate management. First, the stakeholder approach can be significantly strengthened. By focusing on truly material issues, they move into a more central position. Furthermore, corporate reporting becomes more transparent, which can lead to positive effects on the stakeholder side. Secondly, by using the Guiding Principle Materiality, companies are able to simulate possible future scenarios by examining how different probable events affect the reporting elements classified as material.

The European Union's Proposal, published in April 2021 (European Commission, 2021), will give <IR> a further boost as it also emphasizes the importance of non-financial assets and value creation focus. It also underlines the need for a multi-perspective view of the Capitals. Besides, $\langle$ IR $\rangle$ does justice to the approach formulated in the proposal to create a comparable and decision-useful basis for stakeholders. The necessary dovetailing of financial and non-financial or sustainable reporting goes hand in hand with this and has recently been anchored in the IIRC framework. The study results add value to the emerging research field of $\langle\mathrm{IR}\rangle$ and academics. Instead, it also offers added value for managers, shareholders, stakeholders, and policymakers. Therefore, this paper provides theoretical and systematic insights into <IR> and indicates critical practical implications that companies can use to derive their specific strategies to implement and apply <IR $>$.

Author Contributions: Conceptualization: Marcel Mock; data curation: Marcel Mock; formal analysis: Marcel Mock, Nicolás Gonzálvez-Gallego, Stefan Razik; investigation: Marcel Mock; methodology: Marcel Mock, Nicolás Gonzálvez-Gallego, Stefan Razik; project administration: Marcel Mock; resources: Marcel Mock, Nicolás Gonzálvez-Gallego, Stefan Razik; software: Marcel Mock; supervision: Marcel Mock, Nicolás Gonzálvez-Gallego, Stefan Razik; validation: Marcel Mock, Nicolás Gonzálvez-Gallego, Stefan Razik; visualization: Marcel Mock; writing - original draft: Marcel Mock; writing - review \& editing: Marcel Mock, Nicolás Gonzálvez-Gallego, Stefan Razik.

Funding. There is no funding for this research

\section{Abbreviations}

\section{$<\mathrm{IR}>\quad$ Integrated Reporting}

IIRC International Integrated Reporting Council 


\section{References}

1. Adams, C.A., Potter, B., Singh, P.J., \& York, J. (2016). Exploring the implications of integrated reporting for social investment (disclosures). British Accounting Review, 48(3), 283-296. [Google Scholar] [CrossRef]

2. Baldi, S. (1998). Normative versus social constructivist processes in the allocation of citations: A networkanalytic model. American Sociological Review, 63(6), 829-846. [Google Scholar] [CrossRef]

3. Bernardi, C. (2020). Implementing Integrated Reporting Lessons from the Field. Springer. [Google Scholar]

4. Biemans, W., Griffin, A., \& Moenaert, R. (2010). In search of the classics: A study of the impact of JPIM papers from 1984 to 2003. Journal of Product Innovation Management, 27(4), 461-484. [Google Scholar] [CrossRef]

5. Biondi, L., Dumay, J., \& Monciardini, D. (2020). Using the International Integrated Reporting Framework to comply with EU Directive 2014/95/EU: can we afford another reporting façade? Meditari Accountancy Research, 28(5), 889-914. [Google Scholar] [CrossRef]

6. Busco, C., Frigo, M.L., Quattrone, P., \& Riccaboni, A. (2013). Towards integrated reporting: Concepts, elements and principles. In Integrated Reporting (pp. 3-18). Springer. [Google Scholar]

7. Camilleri, M.A. (2015). Environmental, social and governance disclosures in Europe. Sustainability Accounting, Management and Policy Journal, 6(2), 224-242. [Google Scholar] [CrossRef]

8. Camilleri, M.A. (2018). Theoretical insights on integrated reporting: The inclusion of non-financial capitals in corporate disclosures. Corporate Communications, 23(4), 567-581. [Google Scholar] [CrossRef]

9. Cerbone, D., \& Maroun, W. (2020). Materiality in an integrated reporting setting: Insights using an institutional logics framework. The British Accounting Review, 52(3), 100876. [Google Scholar] [CrossRef]

10.Cheng, M., Green, W., Conradie, P., Konishi, N., \& Romi, A. (2014). The International Integrated Reporting Framework: Key Issues and Future Research Opportunities. Journal of International Financial Management and Accounting, 25(1), 90-119. [Google Scholar] [CrossRef]

11.Cortesi, A., \& Vena, L. (2019). Disclosure quality under Integrated Reporting: A value relevance approach. Journal of Cleaner Production, 220, 745-755. [Google Scholar] [CrossRef]

12.Davis, J.H., Schoorman, F.D., \& Donaldson, L. (1997). Toward a stewardship theory of management. Academy of Management Review, 22(1), 20-47. [Google Scholar] [CrossRef]

13.de Villiers, C., Rinaldi, L., \& Unerman, J. (2014). Integrated reporting: Insights, gaps and an agenda for future research. Accounting, Auditing and Accountability Journal, 27(7), 1042-1067. [Google Scholar [CrossRef]

14.Deegan, C., \& Unerman, J. (2011). Unregulated corporate reporting decisions: considerations of systemsoriented theories. Financial Accounting Theory. London: McGraw-Hill. [Google Scholar]

15.Denyer, D., \& Tranfield, D. (2006). Using qualitative research synthesis to build an actionable knowledge base. Management Decision, 44(2), 213-227. [Google Scholar] [CrossRef]

16.Dumay, J., Bernardi, C., Guthrie, J., \& Demartini, P. (2016). Integrated reporting: A structured literature review. Accounting Forum, 40(3), 166-185. [Google Scholar] [CrossRef]

17.Dumay, J., \& Dai, T.M.X. (2014). Integrated thinking as an organisational cultural control. Ritical Perspectives on Accounting Conference. [Google Scholar]

18.Dumay, J., La Torre, M., \& Farneti, F. (2019). Developing trust through stewardship: Implications for intellectual capital, integrated reporting, and the EU Directive 2014/95/EU. Journal of Intellectual Capital, 20(1), 11-39. [Google Scholar] [CrossRef]

19.Eccles, R.G., \& Krzus, M.P. (2010). One Report: Integrated Reporting for a Sustainable Strategy. John Wiley \& Sons. [Google Scholar] [CrossRef]

20.Eisenhardt, K.M. (1989). Agency Theory: An Assessment and Review. Academy of Management Review, 14(1), 57-74. [Google Scholar] [CrossRef]

21.Elsten, C.M., \& Hill, N. (2017). Intangible Asset Market Value Study? Journal of Licensing Executives Society, 52(4), 245-247. [Google Scholar]

22.European Commission (2021). Proposal for a DIRECTIVE OF THE EUROPEAN PARLIAMENT AND OF THE COUNCIL amending Directive 2013/34/EU, Directive 2004/109/EC, Directive 2006/43/EC and Regulation (EU) No 537/2014, as regards corporate sustainability reporting. 0104(537). Available at: [Link]

23.European Union (2014). Directive 2014/95/EU of the European Parliament and of the Council of 22 October 2014 amending Directive 2013/34/EU as regards to disclosure of non-financial and diversity information by certain large undertakings and groups. Official Journal of the European Union, 57(L330), 1-19. Available at: [Link]

24.Fasan, M., \& Mio, C. (2017). Fostering Stakeholder Engagement: The Role of Materiality Disclosure in 
Integrated Reporting. Business Strategy and the Environment, 26(3), 288-305. [Google Scholar][CrossRef] 25.Financial Reporting Council (2011). Cutting clutter. Combatting clutter in annual reports. Available at: [Link] 26.Flick, U. (2018). An introduction to qualitative research (6th ed.). Sage. [Google Scholar]

27.Garfield, E. (1989). Citation-classics and citation behavior revisited. Current Contents, 5, 3-8. [Google Scholar] 28.Gerwanski, J., Kordsachia, O., \& Velte, P. (2019). Determinants of materiality disclosure quality in integrated reporting: Empirical evidence from an international setting. Business Strategy and the Environment, 28(5), 750-770. [Google Scholar] [CrossRef]

29.Green, W.J., \& Cheng, M.M. (2019). Materiality judgments in an integrated reporting setting: The effect of strategic relevance and strategy map. Accounting, Organizations and Society, 73, 1-14. [Google Scholar] [CrossRef]

30.Haller, A. (2017). Integrated Reporting - Die Zukunft der Unternehmensberichterstattung? Zeitschrift Für Internationale und Kapitalmarktorientierte Rechnungslegung, 17(10), 442-447. [Google Scholar]

31.Hannen, S. (2017). Integrated Reporting - Useful for investors? [Münster]. [Google Scholar] [CrossRef]

32.Hartanto, D., Radiman, \& Adhani, A. (2020). Integrated Reporting Quality Assessment. Journal of Security and Sustainability, 9(4), 42-55. [Google Scholar]

33.Huang, X.B., \& Watson, L. (2015). Corporate social responsibility research in accounting. Journal of Accounting Literature, 34, 1-16. [Google Scholar] [CrossRef]

34.International Integrated Reporting Council (IIRC). (2015). Materiality in Integrated Reporting. Available at: [Link]

35.International Integrated Reporting Council (IIRC). (2021). International <IR> Framework. Available at: [Link]

36.Jensen, M.C., \& Meckling, W.H. (1976). Theory of the firm: Managerial behavior, agency costs and ownership structure. Journal of Financial Economics, 3(4), 305-360. [Google Scholar]

37.Kolk, A. (2008). Sustainability, accountability and corporate governance: Exploring multinationals' reporting practices. Business Strategy and the Environment, 17(1), 1-15. [Google Scholar] [CrossRef]

38.Krippendorff, K. (2019). Content Analysis: An Introduction to Its Methodology (4th ed.). SAGE Publications, Inc. [Google Scholar]

39.Krzus, M.P. (2011). Integrated reporting: if not now, when? Zeitschrift Für Internationale Rechnungslegung, 6(6), 271-276. [Google Scholar]

40.La Torre, M., Valentinetti, D., Dumay, J., \& Rea, M.A. (2018). Improving corporate disclosure through XBRL: An evidence-based taxonomy structure for integrated reporting. Journal of Intellectual Capital, 19(2), 338-366. [Google Scholar] [CrossRef]

41.Lai, A., Melloni, G., \& Stacchezzini, R. (2017). What does materiality mean to integrated reporting preparers? An empirical exploration. Meditari Accountancy Research, 25(4), 533-552. [Google Scholar] [CrossRef]

42.Legewie, H. (1994). Globalauswertung von Dokumenten [Global evaluation of documents] In A. Boehm, A. Mengel, \& T. Muhr (Eds.), Texte verstehen. Konzepte, Methoden, Werkzeuge (pp. 177-182). [Google Scholar]

43.Martín-Martín, A., Orduna-Malea, E., Thelwall, M., \& Delgado López-Cózar, E. (2018). Google Scholar, Web of Science, and Scopus: A systematic comparison of citations in 252 subject categories. Journal of Informetrics, 12(4), 1160-1177. [Google Scholar] [CrossRef]

44.Massaro, M., Dumay, J., \& Guthrie, J. (2016). On the shoulders of giants: undertaking a structured literature review in accounting. Accounting, Auditing and Accountability Journal, 29(5), 767-801. [Google Scholar] [CrossRef]

45.Massingham, R., Massingham, P.R., \& Dumay, J. (2019). Improving integrated reporting: A new learning and growth perspective for the balanced scorecard. Journal of Intellectual Capital, 20(1), 60-82. [Google Scholar] [CrossRef]

46.Mayring, P. (2014). Qualitative content analysis: theoretical foundation, basic procedures and software solution. [Google Scholar] [CrossRef]

47.Mayring, P. (2016). Einführung in die qualitative Sozialforschung: Eine Anleitung zu qualitativem Denken [Introduction to Qualitative Social Research: A Guide to Qualitative Thinking] (6th revised). Beltz. [Google $\underline{\text { Scholar] }}$

48.Meyer, J.W., \& Rowan, B. (1977). Institutionalized Organizations: Formal Structure as Myth and Ceremony. American Journal of Sociology, 83(2), 340-363. [Google Scholar]

49.Mio, C., \& Fasan, M. (2014). The determinants of materiality disclosure in integrated corporate reporting. In Working Paper (Issue 9). [Google Scholar]

50.Mio, C., Fasan, M., \& Costantini, A. (2020). Materiality in integrated and sustainability reporting: A 
paradigm shift? Business Strategy and the Environment, 29(1), 306-320. [Google Scholar] [CrossRef]

51.Mishra, N., Nurullah, M., \& Sarea, A. (2021). Perception of Company Leaders on opportunities and Challenges of Integrated Reporting in India. Journal of Financial Reporting and Accounting. [Google Scholar] [CrossRef]

52.Nistor, C.S., Stefanescu, C.A., Oprisor, T., \& Crisan, A.R. (2019). Approaching public sector transparency through an integrated reporting benchmark. Journal of Financial Reporting and Accounting, 17(2), 249-270. [Google Scholar] [CrossRef]

53.Petticrew, M., \& Roberts, H. (2008). Systematic Reviews in the Social Sciences: A Practical Guide. In Systematic Reviews in the Social Sciences: A Practical Guide. Blackwell Publishing. [Google Scholar] [CrossRef]

54.Pfaff, D., \& Zweifel, P. (1998). Die Principal-Agent-Theorie [The principal-agent theory]. Wirtschaftswissenschaftliches Studium, 4(98), 184-190. [Google Scholar]

55.Preuß, J., Niebuhr, J., Schmuland, M., \& Zirn, N. (2019). Does good corporate governance lead to increased integrated reporting quality? Management Studies, 9(3), 95-140. [Google Scholar]

56.Roth, H.P. (2014). Is Integrated Reporting in the Future? Considering the Costs, Benefits, and Role of CPAs. The CPA Journal, March 2014, 62-67. [Google Scholar]

57.Shocker, A.D., \& Sethi, S.P. (1973). An Approach to Incorporating Societal Preferences in Developing Corporate Action Strategies. California Management Review, 15(4), 97-105. [Google Scholar] [CrossRef]

58.Spence, M. (1973). Job Market Signaling. The Quarterly Journal of Economics, 87(3), 355-374. [Google Scholar]

59.Spremann, K. (1990). Asymmetrische Information. (With English summary.). Zeitschrift Fur Betriebswirtschaft, 60(5-6), 561-586. [Google Scholar]

60.Sriani, D., \& Agustia, D. (2020). Does voluntary integrated reporting reduce information asymmetry? Evidence from Europe and Asia. Heliyon, 6(12), 1-11. [Google Scholar] [CrossRef]

61.Tranfield, D., Denyer, D., \& Smart, P. (2003). Towards a Methodology for Developing Evidence-Informed Management Knowledge by Means of Systematic Review. British Journal of Management, 14(3), 207-222. [Google Scholar] [CrossRef]

62.Velte, P. (2021). Archival research on integrated reporting: a systematic review of main drivers and the impact of integrated reporting on firm value. In Journal of Management and Governance. Springer US. [Google Scholar] [CrossRef]

63.Velte, P., \& Stawinoga, M. (2017). Integrated reporting: The current state of empirical research, limitations and future research implications. Journal of Management Control, 28(3), 275-320. [Google Scholar] [CrossRef]

64.Vena, L., Sciascia, S., \& Cortesi, A. (2020). Integrated reporting and cost of capital: The moderating role of cultural dimensions. Journal of International Financial Management \& Accounting, 31(2), 191-214. [Google Scholar] [CrossRef]

65.Vitolla, F., Marrone, A., \& Raimo, N. (2020). Integrated reporting and integrated thinking: A case study analysis. Corporate Ownership and Control, 18(1, Special Issue), 281-291. [Google Scholar] [CrossRef]

66.Vitolla, F., \& Raimo, N. (2018). Adoption of Integrated Reporting: Reasons and Benefits - A Case Study Analysis. International Journal of Business and Management, 13(12), 244-250. [Google Scholar] [CrossRef]

67.Wee, M.A.L.W.P., Tarca, A., Krug, L., Aerts, W., Pink, P., \& Tilling, M. (2016). Factors affecting preparers' and auditors' judgements about materiality and conciseness in integrated reporting. [Google $\underline{\text { Scholar] }}$ 